University of Nebraska - Lincoln

DigitalCommons@University of Nebraska - Lincoln

Bedform movement recorded by sequential single-beam surveys in tidal rivers

R. L. Dinehart

U.S. Geological Survey, rldine@usgs.gov

Follow this and additional works at: https://digitalcommons.unl.edu/usgsstaffpub

Part of the Earth Sciences Commons

Dinehart, R. L., "Bedform movement recorded by sequential single-beam surveys in tidal rivers" (2002). USGS Staff -- Published Research. 369.

https://digitalcommons.unl.edu/usgsstaffpub/369

This Article is brought to you for free and open access by the US Geological Survey at DigitalCommons@University of Nebraska - Lincoln. It has been accepted for inclusion in USGS Staff -- Published Research by an authorized administrator of DigitalCommons@University of Nebraska - Lincoln. 


\title{
Bedform movement recorded by sequential single-beam surveys in tidal rivers ${ }^{\text {is }}$
}

\author{
R.L. Dinehart* \\ US Geological Survey, 6000 J Street, Placer Hall, Sacramento, CA 95819, USA \\ Received 6 March 2001; revised 7 August 2001; accepted 26 September 2001
}

\begin{abstract}
A portable system for bedform-mapping was evaluated in the delta of the lower Sacramento and San Joaquin Rivers, California, from 1998 to 2000. Bedform profiles were surveyed with a two-person crew using an array of four single-beam transducers on boats about $6 \mathrm{~m}$ in length. Methods for processing the bedform profiles into maps with geographic coordinates were developed for spreadsheet programs and surface-contouring software. Straight reaches were surveyed every few days or weeks to determine locations of sand deposition, net transport directions, flow thresholds for bedform regimes, and bedformtransport rates. In one channel of unidirectional flow, the portable system was used to record changes in bedform regime through minor fluctuations of low discharge, and through high discharges near channel capacity. In another channel with reversing flows from tides, the portable system recorded directions of net bedload-transport that would be undetectable by standard bedload sampling alone. Published by Elsevier Science B.V.
\end{abstract}

Keywords: Bedforms; Bedload; Tidal rivers; Sediment transport

\section{Introduction}

An inexpensive hydrographic method is described here for recording the presence and movement of sand-channel bedforms in shallow channels, usually less than $10 \mathrm{~m}$ deep. Although bathymetric-mapping systems for deep ocean basins, harbors, and estuarine environments have become highly sophisticated (US Corps of Engineers, 2001; Hydrographic Society, 2001), the practice of using simpler fathometers to collect bedform profiles longitudinally in rivers and

\footnotetext{
The use of trade, product, industry, or firm names in this report is for descriptive purposes only and does not constitute endorsement of products by the US Government.

* Tel.: +1-916-278-3175; fax: +1-916-278-3071.

E-mail address: rldine@usgs.gov (R.L. Dinehart).
}

tidal channels remains a useful activity. Past examinations of bedform movement in the Mississippi River (Carey and Keller, 1957; Harbor, 1998), the River Idle (Crickmore, 1967), large Dutch rivers (van den Berg, 1987), the Fraser River (Kostaschuk et al., 1989), and the Jamuna River (Ashworth et al., 2000) have depended on repeated passage of single-beam fathometers over known line positions. More recently, transponder arrays (Carling et al., 2000) and multibeam echo sounders (ten Brinke et al., 1999) have been used to derive detailed maps of bedform fields over long river reaches.

In a background discussion on sand waves, Nordin (1971) wrote that ' ...the expense involved in obtaining detailed contour maps [of large areas of a streambed] is generally prohibitive, and more generally, one has available only profiles of the 


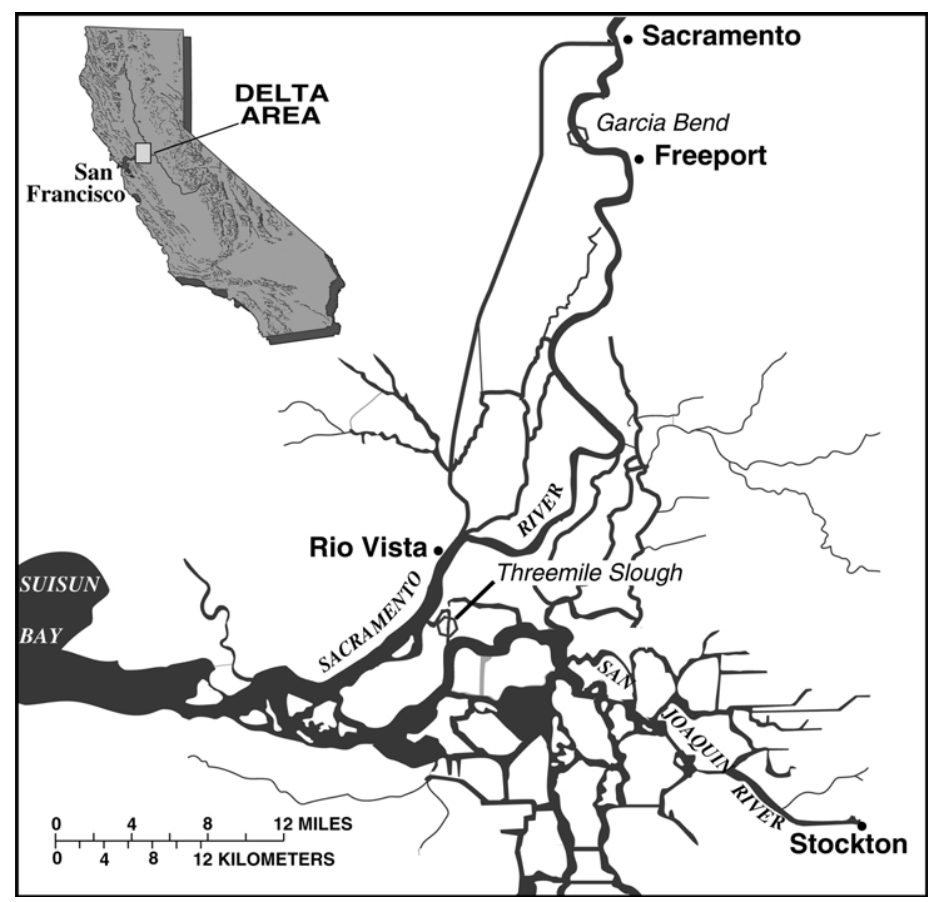

Fig. 1. Location of Garcia Bend and Threemile Slough in the Delta of the Sacramento and San Joaquin Rivers, California.

streambed...' Today, global positioning system (GPS) receivers and digital sonar equipment have become accessible, compact, and inexpensive. Portable computers can be connected with this equipment to collect, process, and visualize detailed bedform data in three-dimensional (3-D) form. In small hydrologic studies, detailed channel topography can be measured repeatedly to record modes and rates of bedform movement, using small boats with no builtin navigational hardware.

This paper describes the survey methods for applying depth data from multiple single-beam transducers to create maps in geographic coordinates. The extraction of bedform profiles from sequential surfacecontour maps of bedform fields is discussed as a technique for measuring bedform movement. Results of bedform-mapping are then illustrated with two example studies in the delta of the Sacramento-San Joaquin Rivers. One example shows a study of bedform development in the Sacramento River over a range of discharges from summer low-flow periods to winter peak discharges. The other example presents the results of bedform surveys over complex topography in a tidal slough.

\section{Purpose of bedform-mapping system}

The portable bedform-mapping system was developed in a larger program to assess sedimentation in the delta of the Sacramento and San Joaquin Rivers (Dinehart and Schoellhamer, 1999). The lower Sacramento River has a drainage area greater than $62,000 \mathrm{~km}^{2}$ as it enters the eastern estuary of San Francisco Bay. The deltaic channels of the lower Sacramento and San Joaquin Rivers have been formed with sediment transported from the drainage basin encompassing the Central Valley and surrounding mountains of California (Fig. 1). These sand-bedded rivers often develop dune bedforms that migrate downstream in unidirectional flow by accreting sediment at a frontal slipface. As the transported sediment enters the delta, the tidal currents affect net transport direction. Although bedload discharge of sand into the delta is only a small percentage of the total sediment discharge, bedload deposition and erosion has the potential to change channel depths and ecosystem habitat within the delta. Therefore, a program to monitor bedform migration with sonar mapping was undertaken by the US Geological Survey (USGS) to 
assess the pathways and timing of bedload-transport through the delta.

Two methods are most often employed for detecting bedform movement with sonar recordings. The simplest method consists of recording the bed elevation at a fixed point, where the passage of bedforms appear as a waveform of changing bed elevation (Nordin, 1971). If two bed elevation records are collected simultaneously, but separated by a streamwise distance on the order of the bedform length, then a bedform speed, or celerity, is calculable from the two records (Crickmore, 1967; Willis, 1968). This method is especially suitable for flumes (Engel and Lau, 1980) and for rivers with high transport rates (Dinehart, 1992). It is less applicable on wide channels because the observed points at near-bank installations may not represent the rest of the bedform field.

In the second method to record bedform movement, one compares a sequence of spatial bedform profiles that have been recorded by sounding along the channel in a boat (Engel and Weibe, 1979). Spatial bedform profiles, surveyed longitudinally at different times, can be statistically correlated to derive a migration rate. Accuracy of the second method is improved by combining a series of adjacent longitudinal profiles into a single contour map of the bedform field. Then, the profile on any line extracted from the bedform map can be correlated with a different profile along the same line on a subsequent map. This refinement of the second method was chosen to derive bedform movement in the study area.

Bedforms in natural channels are not mapped routinely as part of hydrologic monitoring. Their presence may be noted during discharge measurements or occasional fathometer profiles, but bedform-mapping requires specialized equipment and data processing. Because the program to assess bedload-transport included few personnel, a limited equipment budget, and an extensive network of channels, a system was arranged to map bedforms in tidal channels from boats about $6 \mathrm{~m}$ in length. Bedforms were to be surveyed on a regular schedule or throughout hydrologic events by a small crew with single-beam sonar. In this way, bed configurations could be related to local measurements of stream discharge, velocity, and suspendedsediment transport. The details of the system design were ultimately governed by the bedform scales, hydrologic regime, and the surveyed environment.

\section{Constraints on system design}

The hydrographic-surveying community regularly deploys multi-beam or side-scan sonar with differential or kinematic GPS to derive detailed bathymetry of near-shore embayments, estuarine channels, and large rivers (e.g. Davinroy and Naeger, 1986; US Corps of Engineers, 2001). However, high-grade bathymetric systems often are not accessible or may not be necessary for small agencies operating hydrologic networks. If such systems do exist within an organization, the hardware must be relocated quickly to collect data during unexpected changes in river flow. For these reasons, single-beam sonar equipment with differential GPS was considered an expedient alternative for use in the study area. The bedform-mapping system of multiple single-beam transducers was arranged to provide detailed bedform topography with lower cost and greater portability than multibeam sonar systems.

A long, dry season of low-flow dominates the annual hydrograph of the lower Sacramento River, lasting from late spring to late fall. High discharges originate with occasional winter rainstorms, reservoir releases from headwaters and mountain tributaries, and snowmelt runoff. Because high discharges in winter produce high transport rates, bedforms were surveyed in winter months to record the movement of sand to the delta through the lower Sacramento River. Bedform movement was recorded during low-flow seasons to assess the activity of streambeds relative to high discharge periods. Obvious changes in bedform regime were documented whenever stream discharges were greater than $700 \mathrm{~m}^{3} / \mathrm{s}$, which exceeds about $70 \%$ of daily discharges at the USGS gaging station, Sacramento River at Freeport (11447650). To simplify discussion, $700 \mathrm{~m}^{3} / \mathrm{s}$ is used herein as a dividing line between high and lower discharges in the lower Sacramento River.

The benign environment of the study area is ideal for surveying river bedforms. In the lower Sacramento River, flow velocities seldom exceed 1-2 m/s, and water-surfaces are usually calm enough for mapping bedforms from small boats. A dense network of gaging stations provides ample records of watersurface elevation, discharge, and flow direction. Continuous records of water-surface elevation at local gaging stations were used to derive the vertical 
reference of bed elevations to geographic datum. With these favorable elements, the testing of methods for recording bedform movement proceeded rapidly.

Two methods for acquiring bedform profiles with multiple single-beam transducers were investigated: surveying of isolated lines, and surveying a series of overlapping tracks. When only isolated lines were surveyed, the path of the first line was difficult to follow accurately on subsequent surveys. Small deviations in the boat heading could not be corrected quickly enough to maintain a straight line within a few meters of the intended path. At first, bedform profiles along isolated lines were 'straightened' by projecting the measured elevation back to a position along the intended line. This procedure was not needed when four single-beam transducers were later used to survey overlapping tracks.

The survey design had to meet data requirements for the well-known bedform-transport equation (Simons et al., 1965). The bedform-transport quantity $Q_{\text {bf }}$ (volume transport/unit time/unit width) for triangular bedforms can be approximated as

$Q_{\mathrm{bf}}=(H / 2) c\left(1-\lambda_{\mathrm{p}}\right)$

where $H$ is bedform height at the crest, $c$ is bedform celerity (the speed of bedform migration), and $\lambda_{\mathrm{p}}$ is the porosity of the bedform sediment, from (volume of voids)/(volume of total sample). Bedform celerity $c$ is derived from cross-correlation of paired profiles recorded along the same line at different times, or recorded at different points synchronously. For wellsorted sand, the porosity value ranges from 0.3 to 0.4 .

Bedforms in the lower Sacramento River usually migrate too slowly for celerity to be measured from longitudinal profiles on a single day. Therefore, bedform fields were resurveyed a few days later to derive bedform celerity. With bedform celerity at $1 \mathrm{~m} / \mathrm{d}$, the migration distance of $7 \mathrm{~m}$ in one week allowed the positional accuracy $(0.7 \mathrm{~m})$ of GPS to approach $10 \%$ of the migration distance. Height and orientation of bedforms are inconstant as they migrate, so intervals between surveys were minimized to avoid a decrease in coherence between related profiles. This decrease in coherence was expected to occur with a migration distance about twice the average bedform length of $16 \mathrm{~m}$, which was attained in about two weeks during low-flow periods.

With the measurement of bedform dimensions and celerity accomplished, the variables of the bedformtransport Eq. (1) can be given real values. However, bedform-transport rates may not be directly applicable to bedload-transport questions. The reliability of bedload-transport rates derived from bedform migration has been evaluated in flumes and natural channels extensively (Hubbell, 1964; Simons et al., 1965; Crickmore, 1967, 1970; Engel and Weibe, 1979; Engel and Lau, 1980; van den Berg, 1987; Kostaschuk et al., 1989; Dinehart, 1992). These studies have found a narrow range of equivalence between bedform- and bedload-transport rate that limits general use of the method.

After considering the flow conditions and bedform types in the study area, lower-regime dunes appeared to meet criteria for transport computations with the bedform migration method (Simons et al., 1965). When tranquil flow over sand beds promotes the growth of two-dimensional (2-D) sand dunes, such bedforms are expected to act nearly as 'perfect traps' wherein bedform-transport rates approximate bedload-transport rates (Rubin and Hunter, 1982). Therefore, Eq. (1) was used to estimate bedload-transport rates at sites designated as appropriate for bedform-transport computations. Development of the bedform-mapping system was not accompanied by a separate effort to compare bedform- and bedload-transport rates. Only methods for efficient measurement of bedform dimensions and celerity were investigated. The problems of estimating bedload-transport rates from bedform migration in the study area are discussed later, under 'bedformand bedload-transport rates'.

\section{Equipment}

Sonar devices and all surveying hardware were portable and could be mounted on any of three open boats of $6 \mathrm{~m}$ length. A two-person crew was sufficent to handle the boats and surveying duties. Most bedforms were mapped with four single-beam transducers ('multiple transducers') operated synchronously (Datasonics, model PSA-902). The Datasonics model has a resolution of $0.01 \mathrm{~m}$ at a maximum range of $14 \mathrm{~m}$ with a conical beam of $10^{\circ}$, and has time-varying gain circuits to reduce the effect of side lobes. For deeper channels, single-beam 


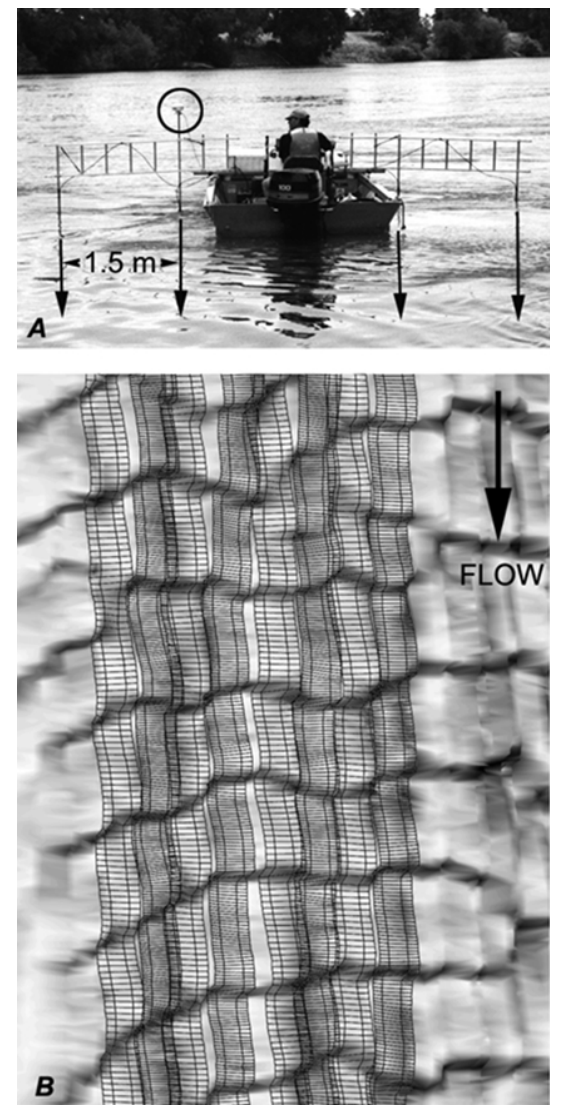

Fig. 2. (A) Four sonar transducers are suspended laterally from survey boat with aluminum ladder sections on the Sacramento River at Garcia Bend. The circle indicates the GPS antenna mounted above a transducer. (B) Meshes represent tracks followed sequentially by upstream and downstream passes along the reach. Each intersection along a mesh represents a bed elevation point. The set of tracks is triangulated to derive the contoured surface on which some tracks are shown superimposed. Each track mesh is $5.8 \mathrm{~m}$ wide.

longitudinal profiles were made with a SonarLite model by Ohmex Instruments. The SonarLite has a resolution of $0.025 \mathrm{~m}$ at a maximum range of $50 \mathrm{~m}$ with a conical beam of $8-10^{\circ}$. Both devices operate with a transducer frequency of $200 \mathrm{kHz}$.

Lateral arrays of single-beam transducers ('sweep systems' or 'swath arrays') have been deployed often in hydrographic-surveying (US Corps of Engineers, 2001; Hydrographic Society, 2001). For economy, a simple frame was constructed from an extension ladder to suspend four transducers across the boat center with a total width of $5.8 \mathrm{~m}$ (Fig. 2A). The four lines of bed elevation measured in a single direction is called a track. Streamwise distances between depth positions were about $0.5 \mathrm{~m}$ along countercurrent tracks and $1 \mathrm{~m}$ along with-current tracks. The bedform field was resolved by maintaining a distance of 2-3 $\mathrm{m}$ between adjacent tracks (Fig. 2B). Reliability of bed elevations was confirmed by comparing overlapping tracks at positions measured with different transducers. About $1 \%$ or less of the recorded depths indicated loss of sonar return or errors while crossing bedform fronts and troughs. The lost and erroneous points along each profile were interpolated graphically to the surveyed profile with a spreadsheet program, using unaffected points as the guide.

A GPS navigation program was used to display and $\log$ position and guide the boat along prearranged grid lines for bedform surveys. The differential GPS device (Trimble Pathfinder ProXR) has a second-bysecond resolution of $0.70 \mathrm{~m}$ (detailed specifications available from Trimble Inc.). In the vicinity of the San Francisco Bay and Delta, US Coast Guard beacons transmit differential corrections to GPS signals, so that separate base stations need not be deployed.

Navigation instruments such as pitch-and-roll sensors to correct for boat attitude were not essential for reliable bedform surveys on the calm waters of the lower Sacramento River and delta. Occasional wakes from passing boats disturbed bedform surveys. Because the wakes were only incidental, only affected short segments of a profile, could be edited out, no real-time system of correction was used. Wakes were further avoided by choosing quiet or less-traveled reaches of river for repeated surveys. Pitch-and-roll during windy weather also made grid lines difficult to follow in a small boat. However, surveys were sometimes rescheduled to calmer days without loss of data, because bedform-transport and flow conditions did not change rapidly in the lower Sacramento River.

A portable computer was used for GPS navigation and sonar-data acquisition. The GPS positions and sonar depths either were (1) acquired into a Microsoft Excel spreadsheet during surveys from the Datasonics model or (2) logged directly by the Ohmex sonar device for subsequent processing in Excel. Position data are sent by the differential GPS receiver at $1 \mathrm{~Hz}$, while the sonar devices send depth data at 
rates between 0.5 and $2 \mathrm{~Hz}$. Separate time stamps were added to GPS positions and depth data at an accuracy of $0.1 \mathrm{~s}$. The GPS positions acquired by the portable computer were in the form of latitude and longitude conforming to the geographic coordinate system WGS84.

The elevation data are available from differential GPS while boating were not accurate enough for use as a vertical reference. Instead, sonar depths were corrected from water-surface elevation to give bed elevation at vertical datum, using stage data recorded at $15 \mathrm{~min}$ intervals at nearby gaging stations. If a surveyed reach was not located at a single gaging station, the water-surface elevation was interpolated from stage records at nearby gaging stations upstream and downstream from the survey site. Interpolated elevations were reliable, given that water-surface slopes in the delta are on the order of $5 \mathrm{~cm} / \mathrm{km}$.

\section{Surveying methods and calculations}

Bedforms were surveyed at reaches suitable for sediment transport measurements in the delta of the Sacramento and San Joaquin Rivers. When a survey reach was selected after reconnaissance soundings, a digital map of the reach was prepared. The GPS navigation program, Fugawi Moving Map Software (Northport Systems), was selected to guide bedform surveys because of the ability to import custom digital maps. For tracking position with the GPS navigation software, grid lines were added to scanned segments of maps with an image-editing program. The straight grid lines were drawn to follow the flow direction and cross perpendicular to bedform fronts. To aid the pilot in guiding the boat along the grid lines, the maps were rotated to align the upstream direction with the vertical direction on the monitor screen. In swifter flows, better alignment with grid lines was obtained by motoring against the prevailing current. The bedform surveys at gridded reaches required from 2 to $5 \mathrm{~h}$ to record, depending mainly on reach length.

A navigational compass was not part of the dataacquisition system, so the effects of its absence were considered. Without a recorded compass bearing, the orientation of the transducer array is known only from GPS positions. As the survey boat is steered along grid lines, it tends to crab, or deviate from a forward heading, in response to wind and turbulent upwellings. To return to the line, the boat heading must be changed temporarily. During the change in heading, the lateral orientation of the boat keel line is unknown with respect to GPS positions. Therefore, two different assumptions might be applied to determine the orientation of the transducer array, depending on the method to calculate migration. Either the boat keel line is assumed parallel with the grid line while the boat crabs across the line, or the trajectory of the GPS antenna across grid lines is assumed parallel with the boat keel line. Keel and grid lines were assumed parallel for the method of projected points; keel and trajectory lines were assumed parallel for plotting tracks of multiple transducers. As a practical matter, the pilot could determine when crabbing of the boat was corrupting the survey, and would cease surveying under those circumstances. A recorded compass bearing is essential for accurate orientation of the transducer array in poor surveying conditions.

A sequence of calculations was followed within a standard spreadsheet program (Microsoft Excel) to provide positions for all transducers. With a set of logged positions in decimal degrees for the trajectory of the GPS antenna on the boat, one can interpolate the antenna position corresponding to the time of each depth measurement. The positions of depth measurements were interpolated from the relative times of the GPS positions and depth measurements. Then, the interpolated positions were converted to California state plane coordinates, in meters, with the software program CORPSCON 5.x for Windows. One transducer was mounted directly below the GPS antenna, so a position was always available at that transducer. The antenna trajectory at the time of each depth measurement was calculated from the preceding and subsequent interpolated positions. The orientation of the transducer array in the horizontal plane was assumed perpendicular to the antenna trajectory. The positions of adjacent transducers at the time of a depth measurement were located along that perpendicular line. The distance from the antenna to a transducer was taken as the hypotenuse of a right triangle with the sides equal to the $x$ and $y$ distances from the interpolated position. The adjacent transducer positions were determined by adding the $x$ and $y$ values to the coordinates of the interpolated position. A positive distance from the GPS antenna gave the starboard transducer 
Table 1

Summary of bedform-transport measurements for Sacramento River at Garcia Bend, California. Mean bedform celerity $c$ from cross-correlation of coincident bedform profiles extracted from topographic contours. Mean bedform height $h$ from integrated area under bedform profiles. Mean velocity cubed from mean channel velocity as measured at the USGS gaging station Sacramento River at Freeport, $6.4 \mathrm{~km}$ downstream from surveyed site. Transport rates represent totals of subdivided sections for a combined width of $60 \mathrm{~m}$

\begin{tabular}{lllll}
\hline Survey interval & $\begin{array}{l}\text { Mean bedform celerity, } \\
c(\mathrm{~m} / \text { day) }\end{array}$ & $\begin{array}{l}\text { Mean bedform height, } \\
h(\mathrm{~m})\end{array}$ & $\begin{array}{l}\text { Bedform-transport rate, } \\
\text { (tonnes/day) }\end{array}$ & $\begin{array}{l}\text { Mean velocity } \\
\text { cubed }\left(\mathrm{m}^{3} / \mathrm{s}^{3}\right)\end{array}$ \\
\hline July 31-August 4, 1998 & 2.01 & 0.22 & 51.2 & 0.18 \\
April 29-May 6, 1999 & 1.15 & 0.29 & 38.2 & 0.19 \\
July 16-20, 1999 & 0.95 & 0.33 & 34.6 & 0.16 \\
July 20-27, 1999 & 1.12 & 0.33 & 42.3 & 0.17 \\
July 27-August 6, 1999 & 1.00 & 0.33 & 38.0 & 0.16 \\
August 6-12, 1999 & 0.43 & 0.32 & 15.6 & 0.10 \\
January 18-25, 2000 & 1.70 & 0.39 & 72.8 & 0.23 \\
April 6-14, 2000 & 1.49 & 0.21 & 35.8 & 0.18 \\
\hline
\end{tabular}

positions, and a negative distance gave the port transducer position.

Surveying of longer reaches did not involve detailed surveys at grids, which were practical only for reaches shorter than $1 \mathrm{~km}$ in length. To assess deposition and scour patterns, a combination of square-wave patterns and longitudinal profiles was used to define channel bathymetry. Channel crosssections were obtained along deep reaches of the lower Sacramento and San Joaquin Rivers with a single-beam transducer (Ohmex SonarLite model). A square-wave pattern was followed to obtain crosssections during continuous passage along the reach. Channel features such as bars were further defined by isolated longitudinal profiles passing over crosssections. The addition of several longitudinal profiles along a reach allowed contouring software to resolve channel bars and shoals. With only the single-beam transducer and a small boat, comparisons between existing maps and present conditions over several kilometers of channel were obtained after 1 or 2 days of surveying. Channel profiles were resurveyed seasonally to monitor changes in bar elevation, bar migration, and bedform regime.

\section{Bedform maps and profiles}

When the geographic coordinates from surveys were processed, the dimensions of bedform fields were examined through 3-D mapping and analysis of longitudinal profiles. To derive the 3-D bedform maps, the original survey tracks were plotted to check the boat path of all transducers. Then, the set of points was interpolated to a rectangular grid to define a contoured surface for the reach (Fig. 2B). The track plots and grid interpolations were prepared with a commercial 3-D plotting and surface-contouring program (Tecplot, Amtec Engineering, Inc.).

Detailed bedform maps were first derived from adjacent survey tracks acquired at the Sacramento River in July and August 1999 (Table 1). Lateral continuity between adjacent survey tracks indicated that the bedform maps were reliably representative of the bedform field. Bedform crests extended laterally for tens of meters. This lateral continuity also indicated that the bedforms were 2-D. The twodimensionality, in turn, implied that sequential bedform profiles could identify the changing position of the bedforms with time.

Profiles were extracted from a series of bedform surveys for bedform celerity, height, and transport rates. At least 20 depths per bedform length greater than $10 \mathrm{~m}$ were acquired at each transducer by motoring at $1 \mathrm{~m} / \mathrm{s}$ while sampling the depth at $2 \mathrm{~Hz}$. The boat speed was chosen to define bedform profiles well. Depth at each point was considered an areal average because the sonar transducer measures sound as returned from a circular area defined by the cone angle of the transducer $\left(10^{\circ}\right.$ in this study). For bedform profiles in depths of $5 \mathrm{~m}$, the diameter of the area was about $0.9 \mathrm{~m}$. Dune crests within the circular area induced occasional spiking, but the profiles were otherwise well defined. 


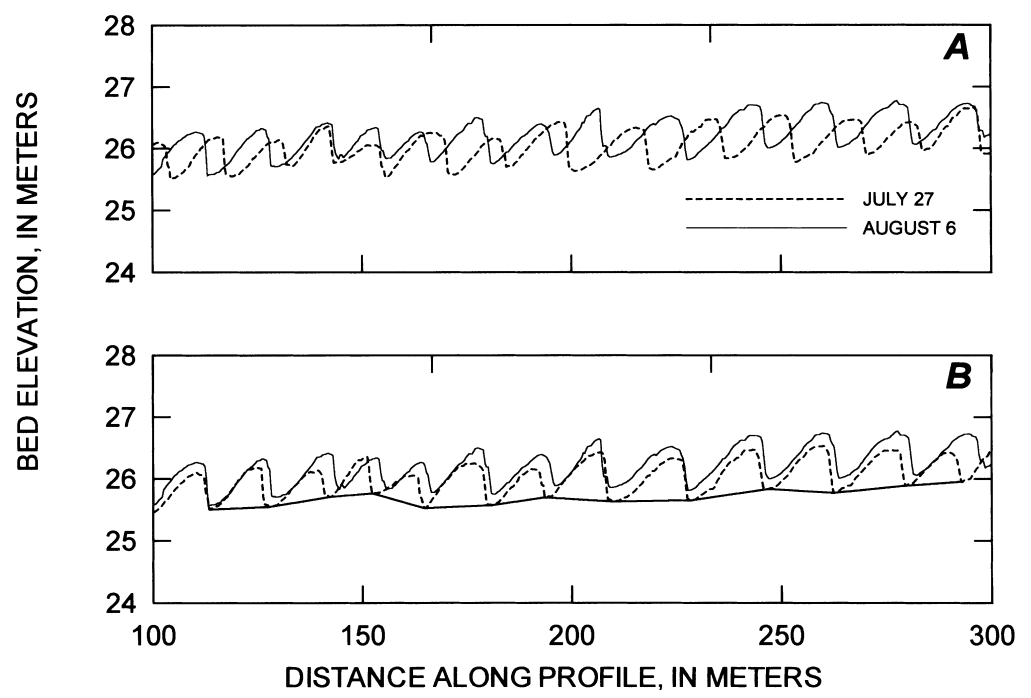

Fig. 3. Bedform profiles at center of channel, Sacramento River at Garcia Bend, July 27 and August 6, 1999: (A) pair of bedform profiles at original positions; (B) the bedform profile of July 27 has been shifted downstream to match the later profile. The trough level as calculated from sequential minima is shown for July 27.
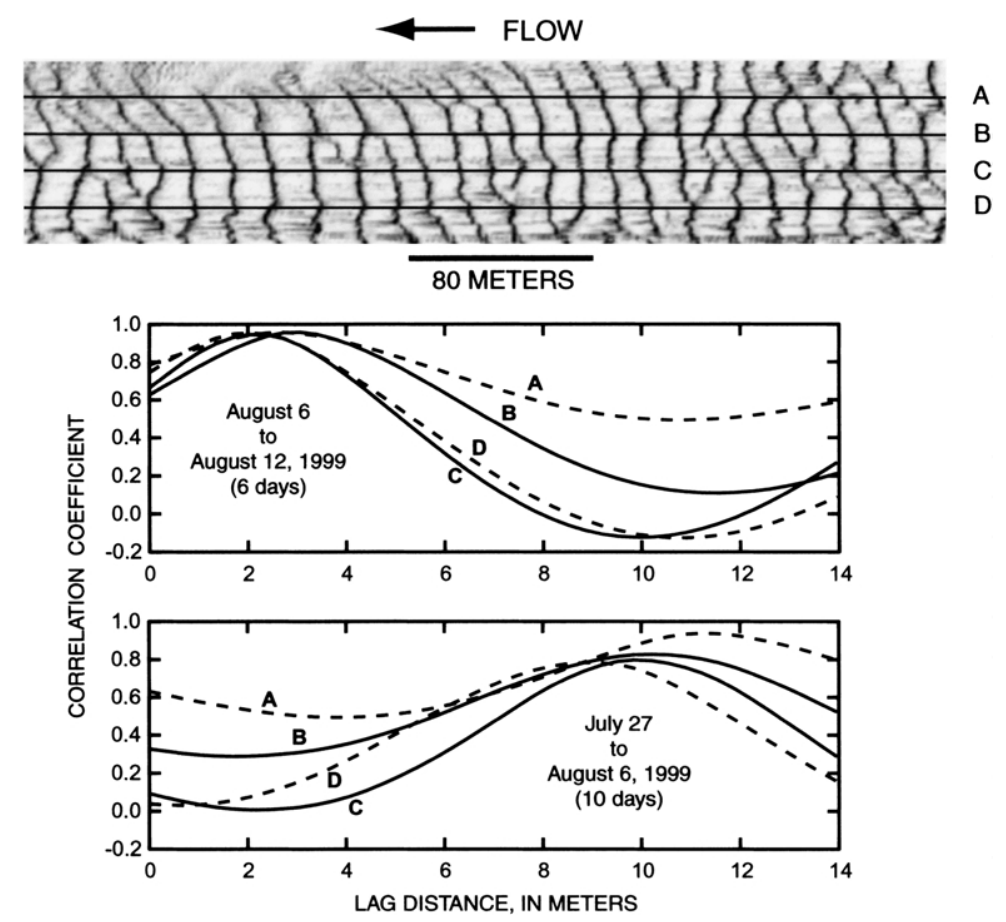

Fig. 4. Cross-correlation curves for four bedform profiles along channel, Sacramento River at Garcia Bend, August 6-12, 1999 (top) and July 27-August 6, 1999 (bottom). Shaded surface plot shows locations of bedform profiles A-D corresponding to correlation curves A-D. 


\section{Derivation of celerity and height from bedform profiles}

Bedform profiles were extracted from bedform maps for numerical computations of celerity and mean height. The line of profile extraction was set perpendicular to bedform fronts to avoid bias in migration rates. Fig. 3 shows an example of two bedform profiles extracted from the same line drawn on separate bedform surveys. Unique sequences of dunes that differ in height and spacing are distinguishable in both profiles when shifted to show correlation. The bedform waves are only quasi-periodic, allowing a cross-correlation function to have a peak correlation lag consistent with the visual correlation. Bedform profiles at several adjacent lines of each survey were cross-correlated with corresponding lines of subsequent surveys to obtain an overall correlation lag $\Lambda$ in meters. Cross-correlation functions of paired bedform profiles for four adjacent grid lines are shown in Fig. 4. Bedform celerity was obtained by dividing the corresponding distance of the peak lag by the time $t$ between surveys, using $c=\Lambda / t$. Higher celerities were measured in areas of smaller bedforms (because smaller bedforms migrate faster) or along the high-velocity core of the channel, where transport rates are higher.

Bedform profiles extracted from bedform maps were preferred over the raw survey data for computing mean bedform height. The bedform profiles can be extracted along any line, with any number of regularly spaced elevations, for numerical purposes. Although the bedform-transport equation (Simons et al., 1965) uses the form $H / 2$ only as an approximation of mean bedform height for triangular section, the volumetric transport of sediment is the product of bedform celerity and the 'average thickness of the sediment layer above a base elevation of zero movement' (Crickmore, 1970). The usual measure of bedform height $H$ is the difference between crest and trough elevation, but trough elevations followed longer undulations over bars along the reach. For the method developed with this study, the area between a trough-based minimum (Fig. 3) and the profile elevation was integrated along the extracted bedform profile. A mean bedform height $h$ was obtained from the integrated area divided by the profile length. In Eq. (1), then, H/2 was replaced by $h$.

\section{Bedform- and bedload-transport rates}

As outlined in Section 3, bedform celerity and height can be applied to calculate a bedform-transport rate. The volumetric rate can be converted to a weight rate by replacing $\left(1-\lambda_{\mathrm{p}}\right)$ in Eq. (1) with the specific weight of bedform sand. This rate is not necessarily the 'bedload-transport rate' that refers to bed material in transport. Under limited flow conditions, 'reasonably accurate values' (Simons et al., 1965) of bedloadtransport can be obtained from computations of bedform-transport. This known disparity between two measures of bedload movement deserves further explanation for applying bedform-transport computations in the study area.

The distinction between bedload- and bedformtransport has been defined in various terms. Hubbell (1964) described the overpassing of dunes by bed material suspended beyond the frontal slipface as a potential flaw of bedform-transport computations. The bypassing sediment was alternately defined by Engelund and Hansen (1967) as 'the part of the total sediment discharge that does not take part in the bed process, and is consequently identified with the suspended load'. Rubin and Hunter (1982) defined 'bedform-transport rate' as distinct from bedloadtransport rate, and included a separate term for bypassing sediment as the 'throughgoing transport rate'.

Simons et al. (1965) showed that transport rates calculated by Eq. (1) were equivalent to sedimentfeed bedload rates in a $2.4 \mathrm{~m}$ wide, recirculating flume for a certain range of conditions. When they formalized the integration of sediment flux along a bedform to derive the bedform-transport rate $Q_{\mathrm{bf}}$, an integration constant $C_{1}$ was added to the right side of Eq. (1). For dune beds, $C_{1}$ is zero. For upper-regime plane beds, $C_{1}$ is the transport rate. For the transitional range (dune beds transitional to low-relief bedforms or plane bed), $C_{1}$ is indeterminate, but represents an increasing fraction of the total transport rate. Although Eq. (1) implies that bedform-transport rates will decrease as bedform height goes to zero, there is no implication that bedload-transport rates also go to zero. This limits the bedform-transport method for deriving bedload-transport rates to regimes of well-formed dunes. Simons et al. (1965) also noted that the agreement between bedform- and 
bedload-transport rate with $0.46 \mathrm{~mm}$ sand was '...reasonably good, except at the higher transport rates where an appreciable percentage of the bed material load was in suspension...' The bed material in the lower Sacramento River is primarily medium sand (mean diameter of $0.4 \mathrm{~mm}$ ), meeting another criterion for observed agreement between bedformand bedload-transport rates.

Suspended-sand concentrations in the study area are small enough during lower discharges that the value of $C_{1}$ described above is insignificant. Suspended-sediment samples have been regularly collected at several sites in the delta of the Sacramento and San Joaquin for decades (US Geological Survey, 1956-1999). In suspended-sediment samples collected by depth integration at the Sacramento River at Freeport (11446750), the mean concentration of sediment coarser than $0.062 \mathrm{~mm}$ (fine sand) rarely exceeds $50 \mathrm{mg} / \mathrm{l}$, except at high discharges. Watersurface slope ranges from 0.00005 at the upper limit of tidal influence to 0.00008 near peak discharge. By applying a theoretical distribution of suspendedsediment (Rouse, 1937) to sand with $0.5 \mathrm{~mm}$ mean diameter, a calculation of vertical sand distribution for the typical depth of $5 \mathrm{~m}$ yields a sand concentration of $1 \mathrm{mg} / \mathrm{l}$ at $0.5 \mathrm{~m}$ above the bed, for a concentration of $300 \mathrm{mg} / \mathrm{l}$ at $0.1 \mathrm{~m}$ above the bed. With low near-bed concentrations of suspended-sand, sediment transport conditions in the study area are consistent with those recommended by Simons et al. (1965) for reliable application of Eq. (1).

The rate of bedload-transport along bedforms of the study area cannot be measured easily by bedload sampling. Although calibration of bedload samplers for gravelly riverbeds has progressed well since their initial development (Hubbell et al., 1987), samplers must be placed carefully on a sand bed to avoid scooping the bed surface or collecting cascading material at the slipface of dunes. The direction of the sampler must also be determined in deep tidal rivers (Ludwick, 1989). In shallow streams, reliable sampling can be accomplished with handheld samplers or with staylines to reel-suspended samplers, but adequate control of bedload samplers is difficult to provide in the deep, sand-bedded channels of the study area.

There are no cableways and few safe bridge walks along the lower Sacramento River from which to deploy bedload samplers. Any bedload sampling must be done with small boats. If the bedload rate in a $120 \mathrm{~m}$ wide reach is 60 tonnes/day, the transport per unit width in the study area is, on average, $0.35 \mathrm{~kg} / \mathrm{m} /$ min. This small amount of sand must be collected at a stationary bed position that is $5 \mathrm{~m}$ below an anchored boat, while avoiding sample contamination by scooping. If the problems of sampler positioning could be resolved, a full day would still be required to obtain a representative set of bedload samples at most channels in the study area. Because bedload-transport rates can vary from zero to four times the mean rate, many samples are required to establish a mean rate at a given point. Carey (1985) offered little encouragement: '...mean transport rates based on a small number of samples at various lateral points have only a remote chance of representing the true lateral distribution'. Gomez et al. (1990) recommended 50100 samples for statistical confidence at each point, but specified 21 samples as a minimum number to characterize the distribution of rates with the passage of a dune. To define bedload-transport rate at five lateral points of a cross-section, then, requires over 100 reliable samples of bedload. A sufficiently large individual sample requires that the sampling period not be less than 3 min (Gaweesh and van Rijn, 1994). Assuming another 3 min between samples, the minimum boat time required to meet statistical demands for accurate bedload-transport rates is $600 \mathrm{~min}$, or $10 \mathrm{~h}$. In the study area, bedload sampling from boats involves substantial cost for the potential benefit of bedload-transport rates. For limited conditions, the data from bedform surveys are suitable to estimate bedload-transport rates of dune beds with greater ease and less cost than bedload sampling.

\section{Examples of single-beam bedform surveys}

Bedform movement was recorded most often at two straight reaches in the delta of the lower Sacramento and San Joaquin Rivers (Fig. 1). Bedforms in unidirectional flow were mapped at the Sacramento River near Garcia Bend. Irregular sand waves in bidirectional flow were mapped at Threemile Slough. The bedform surveys were used to interpret transport variations over discharge hydrographs, identify net direction of bedload-transport, and compute bedform-transport rates. The surveying requirements 


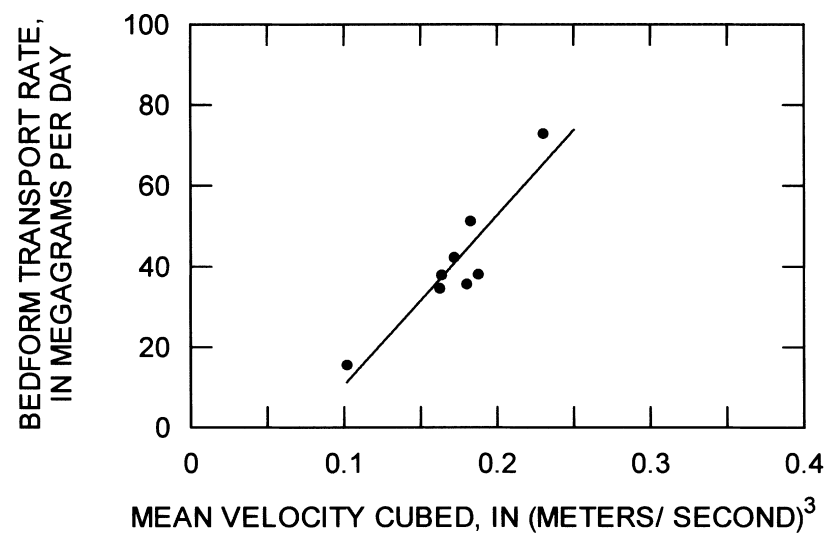

Fig. 5. Bedform-transport measurements at Sacramento River at Garcia Bend, July 31, 1998-April 14, 2000 (Data listed in Table 1).

for each reach are described here, along with results of the bedform analyses.

\subsection{Sacramento river near Garcia Bend}

A survey team investigated the lower Sacramento River and located a straight reach below Garcia Bend (approximately $15 \mathrm{~km}$ south of downtown Sacramento) with 2-D dunes having continuous crests over half the channel width. This reach was chosen for the relative uniformity of bedforms and the minimal effect of bar-scale features on bedform migration. The channel width was $180 \mathrm{~m}$ between leveed banks, with nearly $30 \mathrm{~m}$ at each bank considered inactive for bedform-transport. Bed material was medium sand $(0.25-0.5 \mathrm{~mm})$. Sediment was transported unidirectionally, evolving asymmetric dunes of classic downstream orientation. The surveyed reach was located $6.4 \mathrm{~km}$ upstream from the USGS gaging station, Sacramento River at Freeport (11446750).

Bedform-transport rates were calculated for eight survey intervals for the Sacramento River at Garcia Bend (Table 1). The survey interval of January 18-25, 2000 , occurred in a period of high discharge at the survey site; the other intervals were in periods of lower discharge. Bedform-transport rates were calculated from celerity and mean height of extracted profiles at 4-6 separate lines across the gridded section. The unit rate $(\mathrm{kg} / \mathrm{m} / \mathrm{s})$ at each line was multiplied by the representative width of each subsection, and transport rates for all subsections were summed.
Bedform-transport rates ranged from 16 to 73 tonnes/ day for the measured width of $60 \mathrm{~m}$.

An empirical relation was investigated for bedform-transport rates at Garcia Bend and velocity records measured at the Freeport gaging station. Because bedload-transport is a function of boundary shear stress to the $3 / 2$ power, and shear is a function of mean velocity squared, bedload-transport can be derived as a function of mean velocity cubed $\left(V^{3}\right)$. An ultrasonic velocity meter records velocity hourly at Freeport to compute stream discharge. Although the velocity records include variations from tidal effects, the mean velocity $V$ for entire intervals between bedform surveys was stationary or changed slowly. The velocity recorded hourly at Freeport was cubed $\left(V^{3}\right)$ and then averaged to represent the interval between bedform surveys.

A plot of mean $V^{3}$ with mean bedform-transport rate for each survey interval is shown in Fig. 5. The empirical relation confirmed the expected dependence of transport rates on stream velocity. Scatter in Fig. 5 could result from changes in sediment supply and local water-surface slope at the survey site that would not be reflected in velocity records at the Freeport gaging station. An empirical relation for operational purposes would be improved with velocity records and measurements at the site of bedform surveys.

The bedform surveys at Garcia Bend displayed the changes in bedform dimensions over an area about 60 by $400 \mathrm{~m}$. The discharge threshold for changes in bedform regime at the Sacramento River 

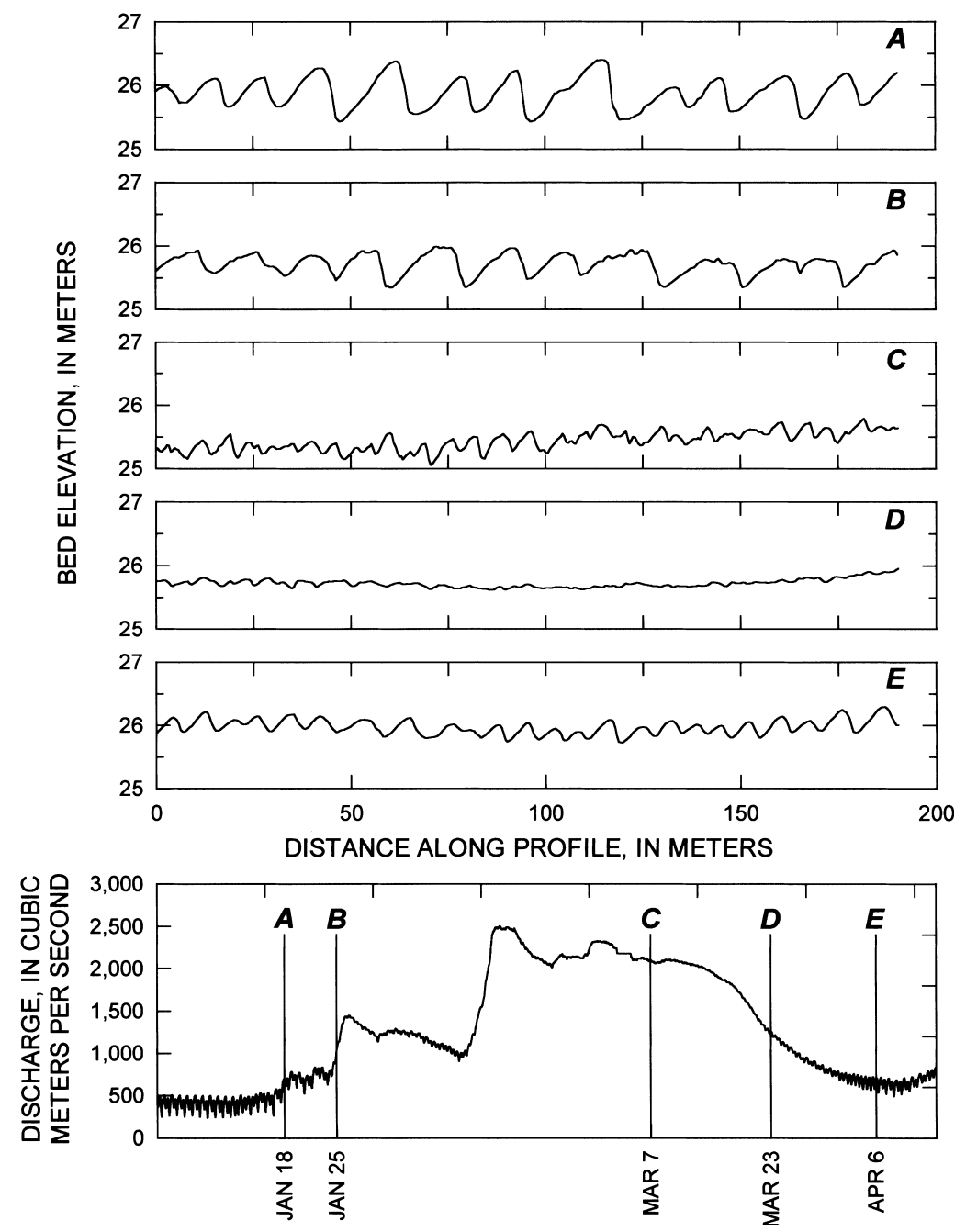

Fig. 6. Series of bedform profiles at center of channel, Sacramento River at Garcia Bend, January 18 through April 6, 2000. Letters in lower plot of stream discharge correspond to date of bedform profiles above.

was correlated with stream hydrographs of the Freeport gaging station. During low-discharge periods, sand bedforms at the survey site were 2-D and migrated at $1 \mathrm{~m} / \mathrm{d}$ or less with crest heights near $1 \mathrm{~m}$. Mean bedform heights ranged from 0.2 to $0.4 \mathrm{~m}$, and mean bedform celerity ranged from 0.4 to $2 \mathrm{~m} / \mathrm{d}$ (Table 1). Bedform wavelengths, measured trough to trough, ranged from 12 to $17 \mathrm{~m}$.

Profiles were extracted from bedform surveys in the Sacramento River at Garcia Bend during January through April 2000 (Fig. 6). Bedform surveys in January 2000 showed the lengthening and flattening of dunes and their superposition by smaller bedforms as stream discharge increased. During high discharge in March 2000, mean bedform heights, at $0.3 \mathrm{~m}$, were similar to those measured at lower discharges, but mean bedform wavelengths, at $6 \mathrm{~m}$, were reduced from a range of 12 to $17 \mathrm{~m}$ measured at lower discharges. Numerous bifurcations of bedform crests in the cross-stream direction caused erratic discontinuities in bedform topography. The 3-D bedforms with shorter wavelengths were surveyed at high discharge along short grid lines that overlapped more closely than typical for lower discharges. 

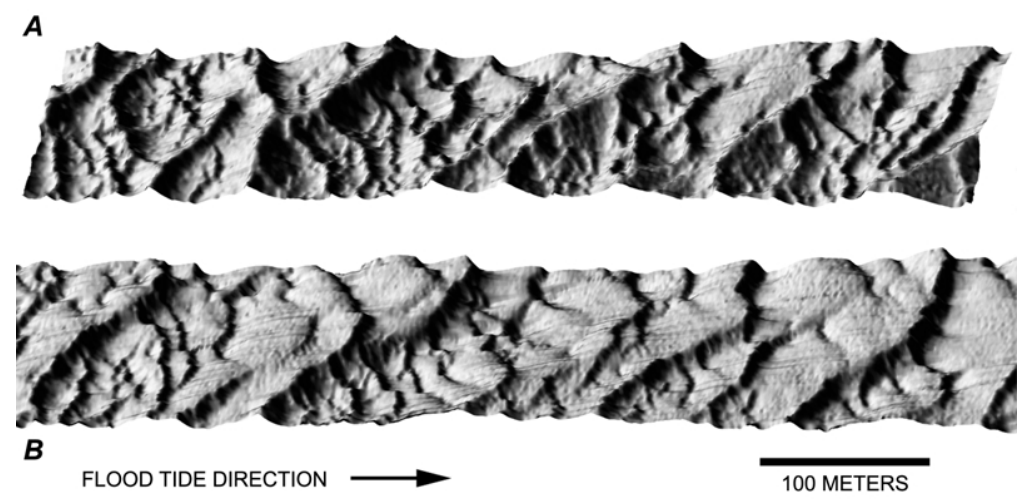

Fig. 7. Shaded surface plots of sand waves in Threemile Slough near San Joaquin River, (A) September 13, 1999 and (B) February $25,2000$. The range of bed elevation is $7 \mathrm{~m}$ from low to high point in this segment of the reach. The entrance from San Joaquin River is to the right of the surface plots.

Bedforms still migrated and distorted too rapidly at high discharge to allow significant correlation of profiles, even with only 4 days between surveys. Repeated bedform surveys on a single day or continuous depth soundings at a stationary point can improve estimates of bedform celerity for transitional regimes (Dinehart, 1992). As described earlier for Eq. (1), bedform-transport rates calculated for periods of high discharge would not be equivalent to bedloadtransport rates.

At high discharge, mean bed elevation of the surveyed reach gradually approached the elevation of bedform troughs measured at lower discharges (cf. profiles A, D in Fig. 6). Following a few weeks of high discharge in February 2000, mean bedform height was diminished from 0.3 to less than $0.1 \mathrm{~m}$ in late March 2000, and the featureless reach remained at the approximate level of previous bedform troughs (Fig. 6). As flow receded in April 2000, bedform surveys indicated the reappearance of dune bedforms with heights and wavelengths smaller than those measured at similar discharge in January 2000.

\subsection{Threemile slough}

About $12 \mathrm{~km}$ upstream from their confluence, the Sacramento and San Joaquin Rivers are connected by a natural channel called Threemile Slough. In this tidal channel, flow is bidirectional, and a net bedload-transport direction is not apparent from flow records. A gaging station at the slough (Threemile Slough near San Joaquin River, 11337080) is operated by the USGS to record water stage and velocity. The gage is located near a sand shoal that forms at the south entrance to Threemile Slough from San Joaquin River. Bedform surveys in the gaged reach were essential for identifying flow processes that affect sediment transport past the USGS gaging station at Threemile Slough.

Bedforms have been mapped periodically in Threemile Slough since 1998 along a $0.5 \mathrm{~km}$ reach near the south entrance to the San Joaquin River (Fig. 7). Where flow depths are less than $10 \mathrm{~m}$, sand dunes migrate with bedform heights often exceeding $3 \mathrm{~m}$ (Dinehart, 2000). By surveying the reach with multiple grid lines instead of isolated lines, an unusual configuration of sand waves in Threemile Slough was identified. A grid length at least six times channel width was surveyed to include the longitudinal variation in bedform sizes. Viewed in planform, the largest dunes in the tidal slough were oriented about $45^{\circ}$ from the leveed banks. The dunes extended across the channel at that angle. Five large dune fronts were separated by $80-100 \mathrm{~m}$ along the reach.

The reach was mapped sequentially to show the origin of the unexpected orientation. Bedform profiles were extracted from bedform surveys made during the summer low-flow period, on September 13 and 29, 1999 (Fig. 7A). Although individual dune profiles in the reach were often symmetrical, dunes nearer the shoal had fronts facing the shoal, indicating southward migration. North-facing dunes at the west side of the surveyed reach usually coexisted with southfacing dunes at the east side. Peak correlation 
coefficients for most pairs of bedform profiles were located near zero lag, because measurable migration distances were only detected in minor, superposed bedforms. However, the migration trend of minor bedforms was visible in comparison of 3-D maps, and corresponded to the steeper fronts in profiles across the channel (Allen, 1985, p. 263).

Bedforms were surveyed in Threemile Slough on February 18 and 25, 2000, when stream discharges in the Sacramento River exceeded $1000 \mathrm{~m}^{3} / \mathrm{s}$. Bedforms across the slough were all migrating southward (Fig. 7B). Peak correlation coefficients for pairs of bedform profiles corresponded to lag distances ranging from 3.0 to $5.5 \mathrm{~m}$. A mean bedform-transport rate of 100 tonnes/day directed toward the San Joaquin River was calculated for the survey interval. The bedform-transport measurement integrated the varying transport over several tidal cycles to yield a useful bedform-transport rate, as noted by Kostaschuk et al. (1989). The bedform-transport measurement gave additional evidence that bedload sediment from the Sacramento River is transported into the San Joaquin River at high discharges.

\section{Summary}

A portable bedform-mapping system was developed in a larger program to study sedimentation in the delta of the lower Sacramento and San Joaquin Rivers. Regular use of the system demonstrated that GPS receivers, single-beam digital sonar, and surfacecontouring software can be combined economically to document channel topography and transport regime throughout a range of discharge. The hardware can be incorporated routinely on small boats to monitor bedform movement in natural channels for hydrologic studies. Optional improvements in sonar and navigational hardware will increase the resolution of bedform dimensions. The expense of preparing bedform maps and deriving bedform movement is no longer prohibitive and is not restricted by a lack of high-grade surveying systems.

The analyses of bedform movement provided results that illustrate the value of the bedformmapping system. A time sequence of bedform surveys at straight reaches provided data for 3-D maps of bedform fields that supported careful scrutiny. The changes in the bedform fields indicated bed regimes and net transport direction. The mean heights and migration rates of 2-D sand dunes were applied in a bedform-transport equation (Simons et al., 1965) to estimate bedload-transport rates for a limited range of conditions. Bedform movement recorded by single-beam surveys at a reach of the lower Sacramento River provided low-cost diagnostic data for unidirectional flow in the dune regime. In a tidally dominated slough, the bedform surveys indicated longitudinally opposed transport directions that would not be easily detectable by bedload sampling.

\section{Acknowledgements}

The development of the bedform-mapping system was supported largely by the CalFed Project, 'Sedimentation in the Delta of the Sacramento and San Joaquin Rivers'. David Schoellhamer provided counsel in conversations on bedform-mapping. Initial drafts of the paper were improved after vigorous review by Jonathan M. Nelson and Paul Carling. The final paper further benefited from referees' comments by Basil Gomez and D. Murray Hicks. Of the many helpful colleagues in the Bay-Delta studies group of the USGS Sacramento office, Rob Sheipline piloted the boats for mapping most often.

\section{References}

Allen, J.R.L., 1985. Principles of Physical Sedimentology. George Allen and Unwin, London pp. 272.

Ashworth, P.J., Best, J.L., Roden, J.E., Bristow, C.S., Klaassens, G.J., 2000. Morphological evolution and dynamics of a large, sand braid-bar, Jamuna River, Bangladesh. Sedimentology 47 (3), 533-555.

van den Berg, J.H., 1987. Bedform migration and bedload-transport in some rivers and tidal environments. Sedimentology 34, 681698.

ten Brinke, W.B.M., Wilbers, A.W.E., Wesseling, C., 1999. Dune growth, decay and migration rates during a large-magnitude flood at a sand and mixed sand-gravel bed in the Dutch Rhine river system. Special Publications International Association Sedimentology 28, 15-32.

Carey, W.P., 1985. Variability in measured bedload-transport rates. Water Resources Bulletin 21 (1), 39-48.

Carey, W.C., Keller, M.D., 1957. Systematic changes in the beds of alluvial rivers. American Society of Civil Engineers, Proceedings, Journal of the Hydraulics Division 83 (HY4), 1331-11331-24. 
Carling, P.A., Golz, E., Orr, H.G., Radecki-Pawlik, A., 2000. The morphodynamics of fluvial sand dunes in the River Rhine, near Mainz Germany. I. Sedimentology and morphology. Sedimentology 47, 227-252.

Crickmore, M.J., 1967. Measurement of sand transport in rivers with special reference to tracer methods. Sedimentology 8 , $175-228$.

Crickmore, M.J., 1970. Effects of flume width on bed-form characteristics. ASCE, Journal of the Hydraulics Division 96 (HY2), 473-596.

Davinroy, R., Naeger, J., 1986. Bathymetry of the Mississippi River in 3-D for river engineering analyses. Proceedings of the Sixth Federal Interagency Sedimentation Conference, March 10-14, 1996, Las Vegas, Nevada, v. 2, pp. V-85-90.

Dinehart, R.L., 1992. Evolution of coarse gravel bedforms: field measurements at flood stage. Water Resources Research 28 (10), 2667-2689.

Dinehart, R.L., 2000. Bedform movement in Threemile Slough near San Joaquin River, CalFed Bay-Delta Program Science Conference Abstracts, October 3-5, 2000, Sacramento, California, pp. 234.

Dinehart, R.L., Schoellhamer, D.H., 1999. Sedimentation in the Delta of the Sacramento and San Joaquin Rivers. Proceedings of the 4th biennial State of the Estuary Conference, San Francisco, Calif., March 17-19, 1999, pp. 75.

Engel, P., Lau, Y.L., 1980. Computation of bedload using bathymetric data. ASCE, Journal of the Hydraulics Division 106 (HY3), 369-380.

Engel, P., Weibe, K., 1979. A hydrographic method for bedload measurement, Environment Canada, preprint for CSCE Hydrotechnical Conference, pp. 35.

Engelund, F., Hansen, E., 1967. A Monograph on Sediment Transport in Alluvial Streams. Teknisk Forlag, Copenhagen pp. 62.

Gaweesh, M.T.K., van Rijn, L.C., 1994. Bedload sampling in sandbed rivers. ASCE, Journal of Hydraulic Engineering 120 (12), 1364-1384.

Gomez, D.W., Basil, D.W., Hubbell, D.W., Stevens Jr, H.H., 1990. At-a-point bed load sampling in the presence of dunes. Water Resources Research 26 (11), 2717-2731.
Harbor, D.J., 1998. Dynamics of bedforms in the lower Mississippi River. Journal of Sedimentary Research 68 (5), 750-762.

Hubbell, D.W., 1964. Apparatus and techniques for measuring bedload, US Geological Survey Water-Supply Paper 1748, pp. 74.

Hubbell, D.W., Stevens, H.H., Jr., Skinner, J.V., Beverage, J.P., 1987. Laboratory data on coarse-sediment transport for bedload-sampler comparisons, US Geological Survey WaterSupply Paper 2299, pp. 31.

Hydrographic Society, 2001. Proceedings of Hydro 2001, 12th Biennial Conference of the Hydrographic Society, Norwich, United Kingdom, March 27-29, 2001, (SP42), The Hydrographic Society, Essex, England.

Kostaschuk, R.A., Church, M.A., Luternauer, J.L., 1989. Bedforms, bed material, and bedload-transport in a salt-wedge estuary: Fraser River, British Columbia, Canada. Journal of Earth Sciences 26, 1440-1452.

Ludwick, J.C., 1989. Bed load transport of sand mixtures in estuaries: a review. Journal of Geophysical Research 94 (C10), $14,315-14,326$.

Nordin, C.F., 1971. Statistical properties of dune profiles, U.S. Geological Survey Professional Paper 562-F, pp.41.

Rouse, Hunter, 1937. Modern conceptions of the mechanics of fluid turbulence. Transactions, ASCE 102 (1965), 463-543.

Rubin, D.M., Hunter, R.E., 1982. Bedform climbing in theory and nature. Sedimentology 29, 121-138.

Simons, D.B., Richardson, E.V., Nordin Jr., C.F., 1965. Bedload equation for ripples and dunes, US Geological Survey Professional Paper 462H, pp. 9.

US Corps of Engineers, 2001. Engineering and Design-Hydrographic-Surveying, EM 1110-2-1003, 22 chapters, separately paginated.

US Geological Survey, 1956-99. Water resources data-California: US Geological Survey Water-Data Reports CA55-2 through CA99-2.

Willis, J.C., 1968. A lag-deviation method for analyzing channel bed forms. Water Resources Research 4 (6), 1329-1334. 